\title{
The Role of Managers in Organizations: Psychological Aspects
}

\section{Gayane Tovmasyan}

$\mathrm{PhD}$, Researcher at "AMBERD” Research Center of the Armenian State University of Economics, Professor at the Public Administration Academy, the Republic of Armenia

\begin{abstract}
Management is the integrating force of the activities carried out in the organization. Management is the whole process of management functions such as planning, organizing, motivating and controlling, which is performed to accomplish the main objectives of the organization by the use of people and other resources. Managers play a decisive role in all management process. They set goals, plan and organize the activities, motivate people and monitor the activities. They are also responsible for themselves and the staff. That is why it is crucial to analyze and discuss the role of managers, their psychological traits and its influence on management process. The article presents the essence of management, the roles of managers by H. Mintzberg. The main skills of managers are discussed. Also, the psychological aspects such as temperament types of managers and psychological types by Carl Jung are analyzed. In order to find out the role of managers and the influence of their psychology on management process, we have carried out a research by survey and interview among employees and managers of different spheres. The results of the survey are analyzed in the article and it is obvious that the effectiveness of management and decision-making process depends on many factors including the psychology of managers. Besides, we have processed and offered a model of manager, which shows the links between the main traits of managers and management process. The main results may be used for further studies in this sphere, also for improving the management process in organizations.
\end{abstract}

Keywords: management, manager, role, psychology, temperament, personality, model, survey.

JEL Classification: M1, M12, D91, C83.

(C) The Author, 2017. This article is published with open access at ARMG Publishing.

\section{Introduction}

Management is a uniting force, when two or more people work together for a common goal, their activities should be coordinated. Manager is the one who sets goals, plans and organizes the activities, motivates human resources and controls the overall procedures. In management process managers have several roles. The study on manager's roles by Mintzberg is discussed in the article. Besides, the main skills and psychological traits of managers impact the quality and efficiency of management. That is why it is of high importance to analyze the psychological aspects of management process, which is carried out in the article.

\section{Literature review and discussion}

According to Mc Farland, "Management is defined for conceptual, theoretical and analytical purposes as that process by which managers create, direct, maintain and operate purposive organization through systematic, coordinated co-operative human effort".

As Henry Fayol defines, "To mange is to forecast and plan, to organize, to compound, to co-ordinate and to control".

Harold Koontz says, "Management is the art of getting things done through and within formally organized group".

Mary Parker Follett defines management as the "art of getting things done through people". A manager is one who contributes to the organization's goals indirectly by directing the efforts of others - not by performing the task himself. On the other hand, a person who is not a manager makes his contribution to the organization's goals directly by performing the task himself.

George R. Terry defines management as a process "consisting of planning, organizing, actuating and controlling, performed to determine and accomplish the objectives by the use of people and other resources".

Thus, management is the sum-total of all those activities that:

determine objectives, plans, policies and programmes; 
secure men, material, machinery cheaply

put all these resources into operations through sound organization

$>$ direct and motivate the men at work,

supervise and control their performance (Pal, Bansal).

Managers are responsible for setting and achieving the firm's goals with and through other people. There have been a number of studies on what managers actually do, the most famous of which conducted by Professor Henry Mintzberg in the early 1970s (Mintzberg, 1973). After following managers around for several weeks, Mintzberg concluded that managers assume multiple roles. A role is an organized set of behaviors, and Mintzberg identified ten roles, which he divided into three groups: interpersonal, informational, and decisional. The informational roles link all managerial work together. The interpersonal roles ensure that information is provided. The decisional roles make significant use of the information (Carpenter, Bauer, Erdogan, 2012).

\section{Interpersonal roles are the following:}

Figurehead - Managers have social, ceremonial and legal responsibilities. They are a source of inspiration. People look up to them as a person with authority, and as a figurehead.

$>$ Leader - Manager provides leadership for the team, organization, and manages the performance and responsibilities of everyone in the group.

> Liaison - Managers communicate with internal and external contacts.

\section{Informational roles are:}

Monitor - Managers regularly seek out information related to the organization and industry, looking for relevant changes in the environment. They also monitor the team, in terms of both their productivity and their well-being.

> Disseminator - Managers communicate potentially useful information to the colleagues and the team.

$>$ Spokesperson - Managers represent and speak for their organization. They are responsible for transmitting information about their organization and its goals to the people outside it.

\section{Decisional roles are:}

D Entrepreneur - Manager creates and controls change within the organization. This means solving problems, generating new ideas and implementing them.

$>$ Disturbance Handler - When an organization or team hits an unexpected roadblock, it is the manager who must take charge.

> Resource Allocator - Managers need to determine where organizational resources are best applied. This involves allocating funding, as well as assigning staff and other organizational resources.

$>$ Negotiator - Managers take part in, and direct important negotiations within the team, department, or organization (Mintzberg's Management Roles).

Performing these roles is the basis of a manager's job.

The effectiveness of management depends on managers' skills. Robert Katz identifies three critical skill sets for successful management professionals: technical skills, human skills, and conceptual skills (Managerial skills).

We have summed up the most important skills for management:

$>$ Leadership skills;

$>$ Influencing, delegating abilities;

$>$ Communication skills;

$>$ Critical thinking skills;

$>$ Collaboration and negotiation skills;

$>$ Project management skills;

$>$ Human resources management skills;

$>$ Time management skills;

$>$ Forecasting skills.

Managers should be fast at planning, should be able to organize and delegate work, motivate people, control the performance, collaborate with others. They should be energetic and goal-oriented, creative and initiator, flexible in new situations, responsible, etc. They should have critical thinking, communication skills, deci- 
sion making methods and techniques, teamwork skills, broad and non-standard thinking, self-development and personal growth needs, psychological ability to influence people, etc.

As the traditional ways of managing have changed, nowadays the managers, instead of traditional planning, organizing, measuring and controlling, should create vision and empower, align the web of relations, inspire and coach and be focused on creating a value.

As the psychological factors have huge impact on management, here we shall analyze the temperament and psychological aspects of managers.

Temperament is the combination of inborn traits that subconsciously affect man's behavior. These traits are arranged genetically on the basis of nationality, race, sex, and other hereditary factors. Such factors will determine if we are outgoing and extroverted or shy and introverted as a person (Cantrell, 2001).

According to a great Greek philosopher Empedocles (495-425 BC), the four primary elements that were used to describe the human temperaments were: fire (that could be warm and dry), air (that could be warm and moist), earth (that could be dry and cold) and water (that could be moist and cold). Another great philosopher who came after Empedocles was Hippocrates (460-377 BC) who developed and seemingly expanded the former's evaluation on human personality and temperaments by using four corresponding body fluids sometimes called humors: blood, yellow bile, black bile and phlegm. According to Hippocrates, the human health depends on the proper balancing of these four humors. After Hippocrates, came Plato (427347 BC) who claimed that humors really had a great contribution into one's behavior. For example, madness of a person was as a result of morbid humors contacting a person's mortal soul. Aristotle (384-322 BC) who was a student of Plato, also embraced the explanations of other great gurus who studied the personality and temperaments of humans. He argued that the shape of the body to some extent reflected the activities of the soul as well and he associated warm and thick blood with strength, and cold and thin blood with intelligence. Though Empedocles used four elements of fire, air, earth and water to describe human personality and temperaments, on the other hand Hippocrates, Plato and even Aristotle looked at the body fluids to categorize some human behaviors. In the later years the theory was then developed by Claudius Galen from Pergamum (131-200 AD) who though recognized the humors or body fluids in order to categorize human personalities and temperaments, also looked into the physiological reasons as the main cause of such human behaviors, moods and emotions. The scholar categorized these behaviors as hot and cold, dry and wet. These were later developed into four temperaments technically referred to as sanguine, phlegmatic, choleric and melancholic. The scholar concluded that if you are a sanguine in which you are influenced by blood then you become cheerful, hearty, outgoing, sturdy/strong, fearless, optimistic and interested in physical pleasures. If you are phlegmatic then you are influenced by phlegm (thick white material that we cough when we have cold) then you become cold, aloof, unemotional, uninvolved, dependable and a trifle dull. If you are choleric then you produce yellow bile from the liver hence you exhibit traits such as anger, hate and have fits of temper (giving in to most bad impulses). If you are described as melancholic then you are driven by a worse black bile from liver hence you are always depressed, unhappy and suicidal (Okal, Ambuyo, Amukowa, 2012).

The temperament type influences the behavior of a manager in the organization.

Managers with sanguine temperament are impulsive, warm-hearted, pleasant, lively and optimistic, sociable and charismatic. They enjoy social gatherings, making new friends. They are usually quite creative, sensitive, compassionate, talkative, not shy and romantic. The negative is that they are chronically late, and tend to be forgetful and sometimes a little sarcastic. Often, when they pursue a new hobby, they lose interest as soon as it ceases to be engaging or fun. They have no lack of confidence.

Managers with choleric temperament are fundamentally ambitious, they have a lot of aggression, energy. They are task oriented people and are focused on getting a job done efficiently. They can dominate people and become dictatorial. Many great charismatic military and political figures were choleric. They like to be in charge of everything and are good at planning, as they often can immediately see a practical solution to a problem. However, they can quickly fall into deep depression or moodiness when failures befall them.

The melancholic temperament is introverted, considerate and very cautious. They are organized and schedule oriented. Melancholics can be highly creative in activities such as poetry, art. Because of their sensitivity and thoughtfulness they are susceptible to depression and moodiness. Often they are perfectionists. Their caution enables them to prevent problems. Melancholics prefer to avoid much attention and prefer to remain in the background. 
The phlegmatic temperament is relaxed and quiet. Phlegmatics tend to be content with themselves and are kind. Phlegmatics are consistent, they can be relied upon as steady and faithful friends. They are affectionate, make friends easily. They tend to be good diplomats. Phlegmatics prefer to observe and to think on the world around them while not getting involved. They may try to inspire others to do the things which they themselves think about doing. They may be shy and often prefer stability to uncertainty and change. They are consistent, relaxed, calm, rational, curious, and observant, qualities that make them good administrators (Educational leadership).

Carl Jung, who was a Swiss psychologist and psychotherapist best known for his founding of analytical psychology and his work "Psychological Types", has built his original typology on:

two personality attitudes: extroversion and introversion;

four functions (or modes of orientation): thinking, sensation, intuition, and feeling.

The four functions are divided into what Jung called rational (or judging) and irrational (or perceiving) functions. Thinking and feeling are rational, according to Jung, while intuition and sensations are irrational.

Introversion, according to him, is one's focus on inner world, while extroversion is one's focus on the outside world (Jung, 1971).

\section{Methods}

For the analysis, we have carried out a sociological survey among employees and managers. The survey was done by questionnaires with open and closed questions, and by interview method. 200 people participated in the survey, $60 \%$ of which were workers. Besides the method of analysis and synthesis was used.

\section{Results}

The aim of the above mentioned survey was to find out how workers and managers think about the role of managers in organization and whether the psychology of managers influence management process.

To the question what skills managers should have, participants have answered:

Communication skills $-57.97 \%$;

Decision-making abilities - $75.36 \%$;

Professional knowledge and practice - 76.81\%;

Time management skills $-55.07 \%$;

Skills for negotiating and influencing people $-66.22 \%$;

Leadership skills $-69.57 \%$;

$>$ Forecasting and planning skills $-55.07 \%$;

$>$ Ability to work with teams $-63.77 \%$;

$>$ Organizing and monitoring skills $-75.36 \%$.

Here we see, that the most important skills according to our participants are: professional knowledge and practice, decision-making abilities, organizing and monitoring skills.

Besides, people have also mentioned the following skills:

$>$ to have moral description;

$>$ to have clearly developed mechanisms of encouragement and punishment;

$>$ to have life experience;

$>$ to be able to find non-standard solutions;

$>$ to be friendly and humanistic;

$>$ to understand the psychology of employees and, accordingly, to show each a specific approach in order to increase the efficiency of work;

$>$ to be aware of the working conflicts and to solve them;

$>$ to be an example for others.

According to the results of the survey, the best manager is the one who is loved and respected by workers. The $93 \%$ of the participants thinks so, and the other $7 \%$ thinks that employees must be afraid of the manager (Figure 1, see Appendix).

Besides, here are some interesting opinions of our participants worth presenting: 
Love and fear is not important, the most important is that the manager fits the position and in that case the staff will obey him.

$>$ The best manager is the one who works very seriously and professionally and provokes both love and fear when needed.

$>$ The love and fear do not happen in real life. Few people really assess the manager during his work. The most important is the respect towards the manager.

$>$ The best manager is the one who is reliable.

$>$ Both fear and respect are important.

To the question, whether psychological traits of the manager influence the efficincy and quality of management process, people have answered:

$>$ Yes $-73.53 \%$ of the participants think so;

$>$ No $-0 \%$ of the participants think so;

$>$ Partly $-22.06 \%$ of the participants think so;

$>$ I don't know $-4.41 \%$ of the participants think so.

According to the results of the survey, the best manager must have Phlegmatic (66.67\% of participants think so) and Sanguine $(50.72 \%$ of participants think so) temperaments. $2.90 \%$ of the participants mentioned Choleric and nobody mentioned Melancholic.

According to the opinion of $80 \%$ of the participants, the best managers are extroverts, and $20 \%$ of participants think, that the best managers' personality type must be introvert. However, some people mention, that it depends on the sphere. According to them, the traits of business sphere managers and that of state security are different.

According to the survey, the work efficiency depends on:

$>$ Workers, as they are performers $-1 \%$ of participants think so.

$>$ Managers, as they plan, organize, motivate and supervise $-16 \%$ of participants think so.

$>$ Both, workers and managers $-83 \%$.

According to the participants, the features of the best managers in the 21th century are as follows:

$>$ Honest $-34.78 \%$ of participants think so;

$>$ Fair $-47.83 \%$ of participants think so;

$>$ Kind $-23.19 \%$ of participants think so;

$>$ Clever $-69.57 \%$ of participants think so;

$>$ Far-sighted $-72.46 \%$ of participants think so;

$>$ Cunning $-26.09 \%$ of participants think so;

$>$ Flexible $-71.01 \%$ of participants think so;

$>$ Measured $-56.52 \%$ of participants think so;

$>$ Balanced $-59.42 \%$ of participants think so;

$>$ Orator $-30.43 \%$ of participants think so.

So, the most important features of managers encompass being far-sighted, flexible and clever. Besides, as participants have mentioned, the manager must be able to collaborate with employees, work with teams and groups, involve groups in decision-making process, use the methods of participative management.

Thus, the results of our survey show, that the psychological aspects of managers greatly influence management process and in order to improve the management quality, it is crucial to analyze these factors.

Based on the analysis, we have suggested an integrated model of manager, including the above mentioned skills as a whole (Figure 2, see Appendix).

The model is an integrated approach for evaluating the role of managers in the organization. The model shows the set of links between the main skills of managers' and the management process, the results of managerial work. Besides, we have also feedback, complaints and suggestions during and after the management process, which lets us improve the performance during the whole process: in the beginning, in the middle and at the end. 


\section{Conclusion}

Concluding, we may say, that management activity is the result of a person's mental activity and many factors influence the efficiency of that activity, such as: the role of the manager, the professionalism and knowledge of the manager, his leadership, decision-making and communication skills, his personality and temperament type, psychological aspects, etc. Our survey revealed many essential aspects that might be useful for improving the quality of management process. As managers are humans, they have psychology and it is of high priority to take into account the psychological aspects of management in organizations.

\section{References}

1. Cantrell, P. (2001). A study of temperament, Pennsylvania, p. 7.

2. Carpenter, M., Bauer, T., Erdogan B. (2012). Principles of Management, p. 15. Retrieved from: https://2012books.lardbucket.org/pdfs/management-principles-v1.0.pdf.

3. Educational leadership. Retrieved from: http://teachingteacher.weebly.com/four-temperaments.html.

4. Jung, C. (1971). Collected Works of C. G. Jung, 6, 2nd ed., Princeton University Press, pp. 330-407.

5. Managerial skills - 3 types of skills each manager will need. Retrieved from: http://www.entrepreneurshipinabox.com/202/managerial-skills/.

6. Mintzberg, H. (1973). The Nature of Managerial Work. New York: Harper \& Row.

7. Mintzberg's Management Roles, Identifying the Roles Managers Play. Retrieved from: https://www.mindtools.com/pages/article/management-roles.htm.

8. Okal, B. O., Ambuyo, B. A., Amukowa, D. N. (2012). The Functionality of Four Temperaments and Communication Theories towards the Realization of Peaceful General Elections in Kenya. Journal of Sociological Research, 3(1), 57-58.

9. Pal, K., Bansal, H. (2012). Management Concepts and Organizational Behaviour, pp. 3-9. Retrieved from: http://www.ddegjust.ac.in/studymaterial/mcom/mc-101.pdf.

\section{Appendix}
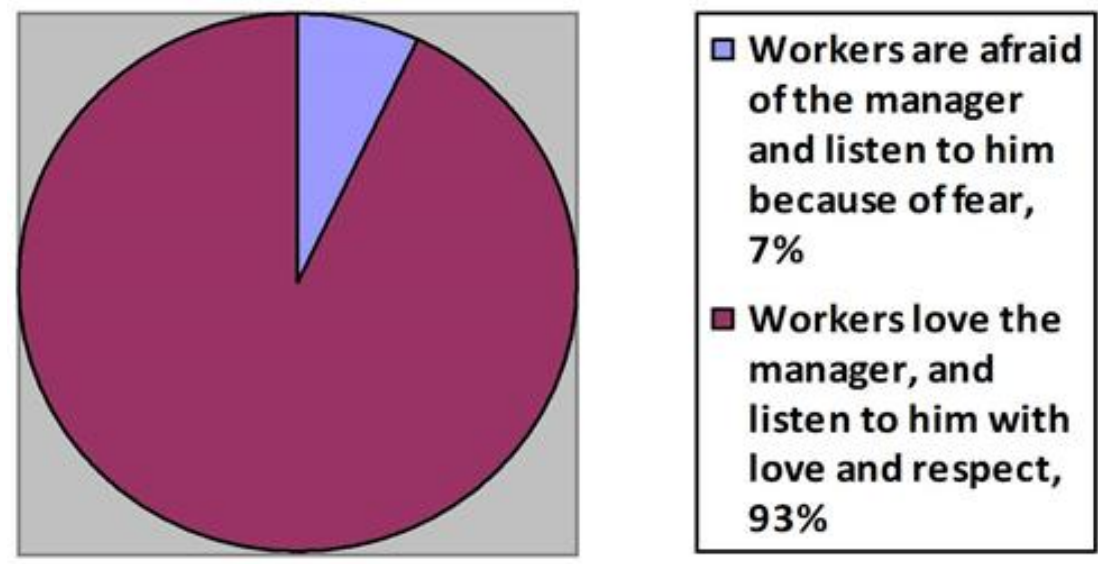

Figure 1 


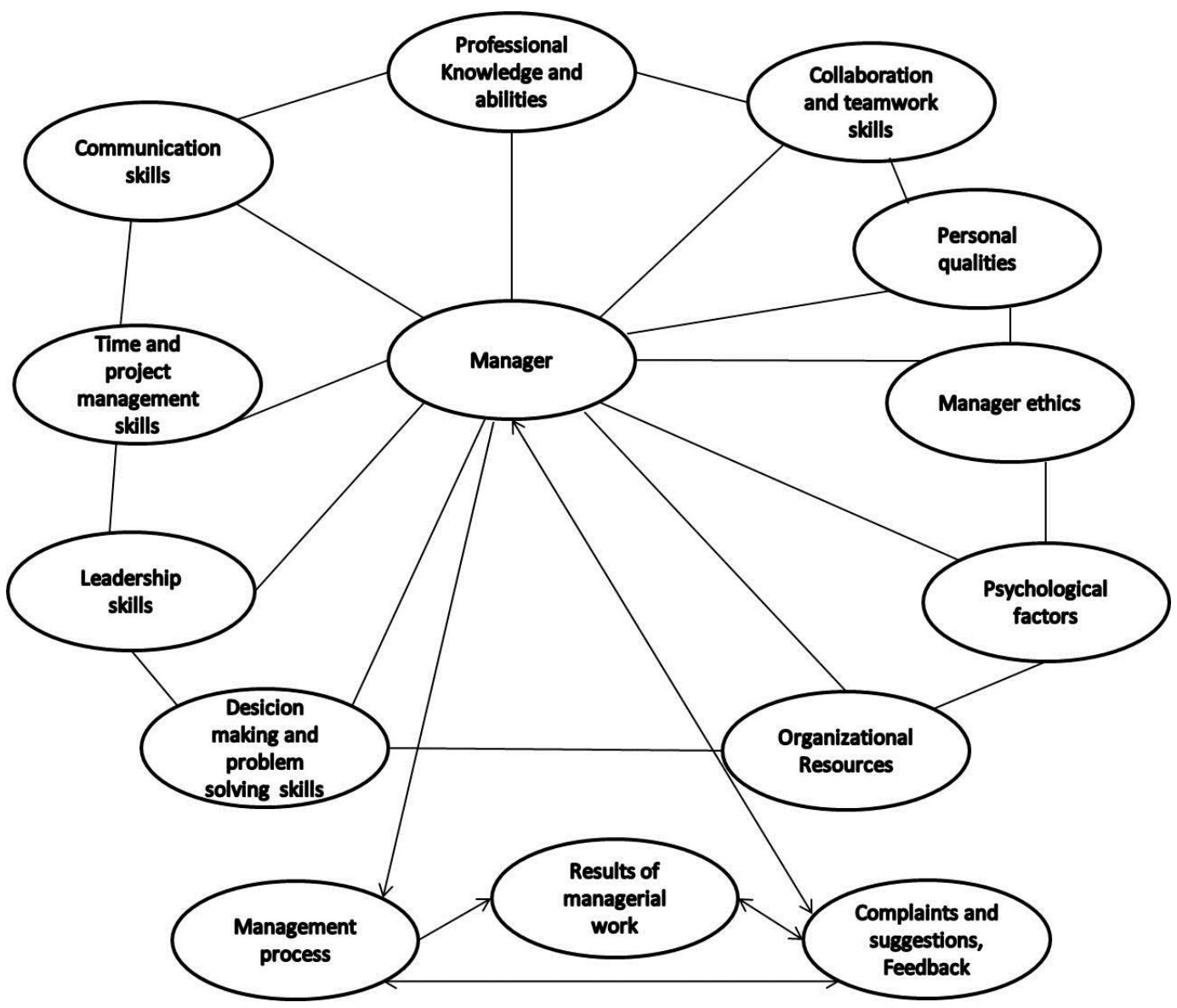

Figure 2 